\title{
Treatment of Large Periapical Lesions without Surgical Approach: Report of Three Cases
}

\author{
Hakan Arslan ${ }^{1}$, Ertuğrul Karataş ${ }^{1}$, Çağatay Barutcugil ${ }^{2}$, H. Sinan Topçuoğlu ${ }^{1}$, Halit \\ Aladağ ${ }^{3}$ \\ ${ }^{1}$ Research Assistant, Ataturk University, Faculty of Dentistry, Department of Endodontics, Erzurum, TURKEY \\ ${ }^{2}$ Assistant Professor, Ataturk University, Faculty of Dentistry, Department of Restorative Dentistry, Erzurum, TURKEY \\ ${ }^{3}$ Assistant Professor, Ataturk University, Faculty of Dentistry, Department of Endodontics, Erzurum, TURKEY
}

\section{Key Words}

Non-surgical treatment, periapical lesion, root canal treatment.

\section{Correspondence:}

Hakan Arslan

Atatürk University

Faculty of Dentistry

Department of Endodontics

25240 Erzurum, Turkey

e-mail: dt_hakan82@hotmail.com

\begin{abstract}
The aim of this paper is to present the non-surgical management of three cases with large periapical lesions. Surgical treatment of large periapical lesions is often subject to various complications. Therefore, a non-surgical approach should be considered for the management of these lesions. The first was a maxillary lateral incisor with a periapical lesion of endodontic origin in a 19-year-old female patient, the second affected a maxillary central incisor in a 21-year-old female patient and the third was a mandibular molar in a 36-year-old male patient. The canals were prepared using crown down technique. During root canal treatment, sodium hypochlorite was used for irrigation and calcium hydroxide was used for the intra-canal dressing. Clinical evaluation was performed after 10 days. The teeth were asymptomatic and the root canals were obturated using lateral compaction technique. The patients were recalled at 3, 6 and 12 months. These radiolucent periapical lesions were treated successfully without surgical approach.
\end{abstract}

(Int Dent Res 2012;2(1):17-22)

\section{Introduction}

Caries, dental surgical procedures, and trauma typically cause infection of the dental pulp. Subsequent total pulpal necrosis commonly occurs, followed by the formation of a periapical lesion (1). Unless a patient visits a dentist due to discomfort or acute pain, such lesions are typically diagnosed by the dentist during routine radiographic examination (2).

Most (>90\%) periapical lesions are endodontic in origin; lesions originating from infected root-canal spaces can be classified as dental granulomas, radicular cysts, or abscesses $(3,4)$. However, definitive diagnosis requires histological examination. The likelihood that a radiographically visible cyst is present increases when the lesion (i) is periapical and involves one or more teeth with nonvital pulp, (ii) is $>200 \mathrm{~mm}^{2}$ in size, (iii) is characterized radiographically by a circumscribed, well-defined, radiolucent area bound by a thin radiopaque line, or (iv) produces a straw-colored fluid upon aspiration or as drainage through an accessed root-canal treatment (5).

Treatment options include non-surgical rootcanal treatment, apical surgery, and extraction. Initial non-surgical root-canal treatment must be considered to control large periapical lesions. When such treatment does not successfully resolve the periradicular pathosis, additional treatment options, such as curettage, apical resection, marsupialization, and tube decompression, should be considered (6). 
This paper describes the non-surgical management of three cases with large periapical lesions.

\section{Case Reports}

\section{Case Report I}

A 19-year-old female patient was referred to Ataturk University, Faculty of Dentistry, Department of Endodontics for treatment of the maxillary left lateral incisor tooth. The reason for consultation was discoloration of the tooth. Clinical examination revealed that the tooth was discolored, with a composite restoration and slight sensitivity to percussion and palpation, but there was no mobility. The left lateral incisor failed to respond to thermal and electric testing. Radiographic evaluation demonstrated a wide canal and a radiolucent lesion approximately $7 \mathrm{~mm}$ in diameter around the apex (Fig. 1A).

A non-surgical endodontic therapy of the maxillary left central incisor was planned. After applying a rubber dam, the access cavity was prepared without local anesthesia. Working length was determined by an electronic apex locator (Propex, Dentsply-Maillefer, Ballaigues, Switzerland). Canal preparation was conducted using the crown down technique with Hero Shaper (Micro Mega, Besançon, France) instruments and $\mathrm{K}$ files. \% 19 EDTA (File-Eze, Ultradent, South Jordon, USA) was used as a canal lubricant. During the preparation, 2, $5 \%$ sodium hypochlorite irrigating solution was administered between file applications. Calcium hydroxide paste was placed into the canals with lentulo filler. The tooth was temporarily restorated with Cavit (ESPE Dental AG, Seefeld, Germany). Clinical evaluation was performed after 10 days. The tooth was asymptomatic and the canals were obturated by means of the lateral condensation technique for the root canal, using gutta-percha and Sealapex sealer (Kerr, Salerno, Italy) (Fig. 1B).The patient was recalled at 3, 6 and 12 months. After one year, the patient exhibited healthy dental structures and the absence of the radiolucent periapical lesion (Fig. 1C, 1D).

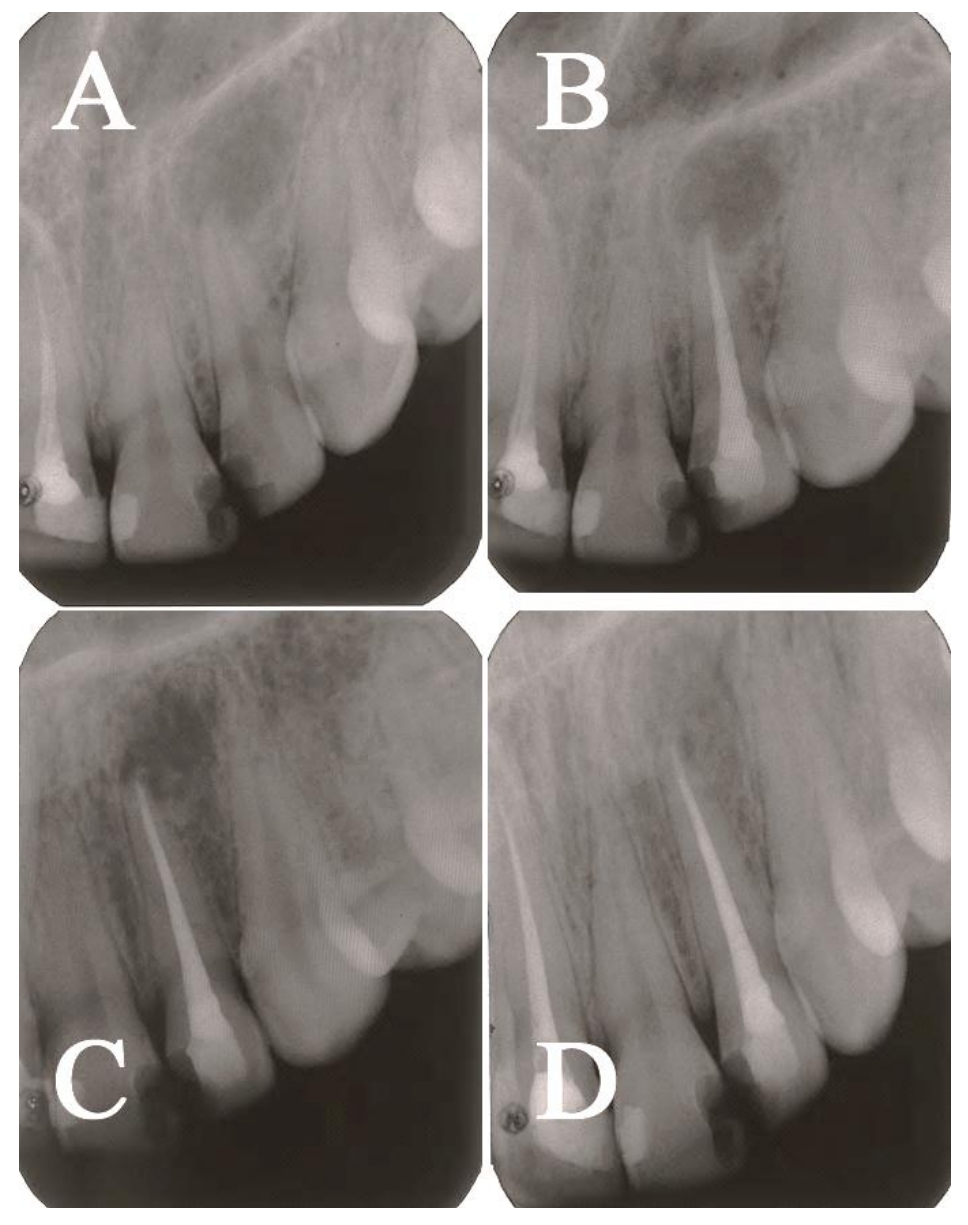

Figure 1. (A) I nitial radiograph revealed large periapical lesion; (B) radiograph of the root canal obturation; (C) radiograph at 180 days, with good periapical and periodontal repair; (D) radiograph at one year, revealing complete repair. 


\section{Case Report II}

A 21-year-old female patient under orthodontic treatment was referred to Ataturk University, Faculty of Dentistry, Department of Endodontics for treatment of the maxillary right central incisor tooth. Clinical examinations revealed a tooth was discolored, with a composite restoration and slight sensitivity to percussion and palpation, but there was no mobility. Clinical examination of the soft tissues showed fistulae. The right maxillary central incisor failed to respond to thermal and electric testing. Radiographic evaluation demonstrated a wide canal and a radiolucent lesion approximately 9 $\mathrm{mm}$ in diameter around the apex (Fig. 2A).

A non-surgical endodontic therapy of the maxillary left lateral incisor was planned. After applying a rubber dam, the access cavity was prepared without local anesthesia. The canal was prepared in the same manner as that described in the previous case report and was temporarily restored with Cavit (ESPE Dental AG, Seefeld, Germany). Clinical evaluation was performed after 10 days. The tooth was asymptomatic, and the canals were obturated by means of the lateral condensation technique for the root canal, using gutta-percha and Sealapex sealer (Kerr, Salerno, Italy) (Fig. 2B).The patient was recalled at 3, 6 and 12 months. After one year, the patient exhibited healthy dental structures and the absence of the radiolucent periapical lesion (Fig. 2C, 2D).

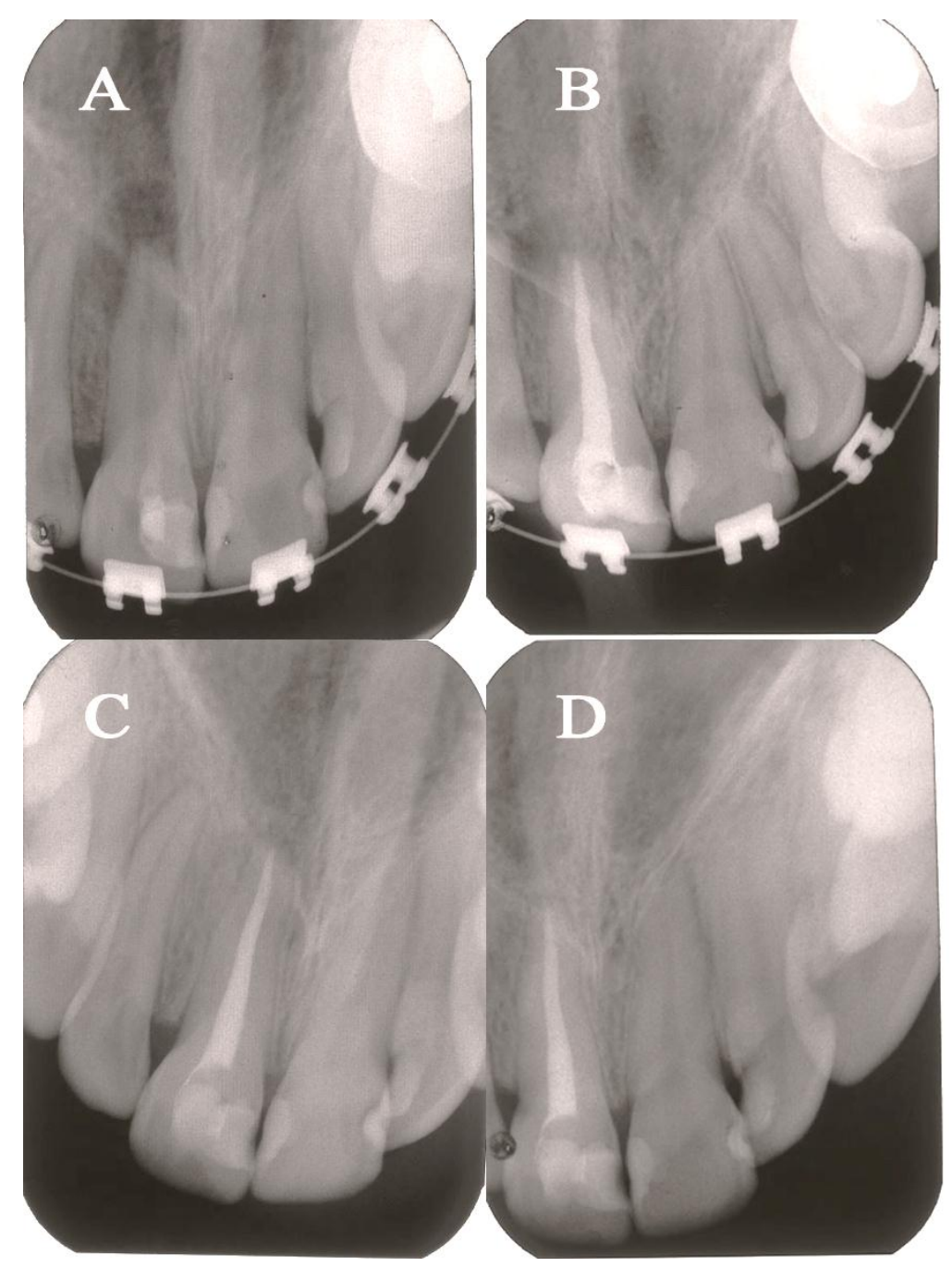

Figure 2. (A) Initial radiograph revealed large periapical lesion in the patient under orthodontic treatment; (B) radiograph after obturation; (C) radiograph at 180 days, with good periapical and periodontal repair; (D) radiograph one year later. 


\section{Case Report I I I}

A 36-year-old male patient was referred to Ataturk University, Faculty of Dentistry, Department of Endodontics for treatment of the mandibular right first molar tooth. Upon questioning, the patient reported that the tooth was generally comfortable, yet with minor pain during mastication. Initial endodontic treatment had been performed almost one month prior. Clinical examination revealed a tooth with a wide cavity open to the oral environment. The tooth was slightly sensitive to percussion and palpation. Radiographic evaluation demonstrated mesial root canals that presented a $45^{\circ}$ curvature and distal root canals with guttapercha cones (Fig 3A). There was loss of continuity of the periodontal ligament and lamina dura, and a periapical radiolucent lesion, measuring approximately $8 \mathrm{~mm}$ in diameter and completely involving the furcation region, was associated with both roots.

A non-surgical endodontic therapy of the mandibular right first molar was planned. After applying a rubber dam, preoperative asepsis was made with $1 \%$ sodium hypochlorite. The canals were prepared in the same manner as that described in the previous case reports, and the tooth was temporarily restorated with Cavit (ESPE Dental AG, Seefeld, Germany) (Fig. 3B). Clinical evaluation was performed after 10 days. The tooth was asymptomatic, and the canals were obturated by means of the lateral condensation technique for the four root canals, using gutta-percha and Sealapex sealer (Kerr, Salerno, Italy). The patient was recalled 6 months later, but he came about one year later. Clinical examination showed no sensitivity to percussion or palpation, and the soft tissues were healthy. Radiographic examination showed the progressive process of healing (Fig. 3C).

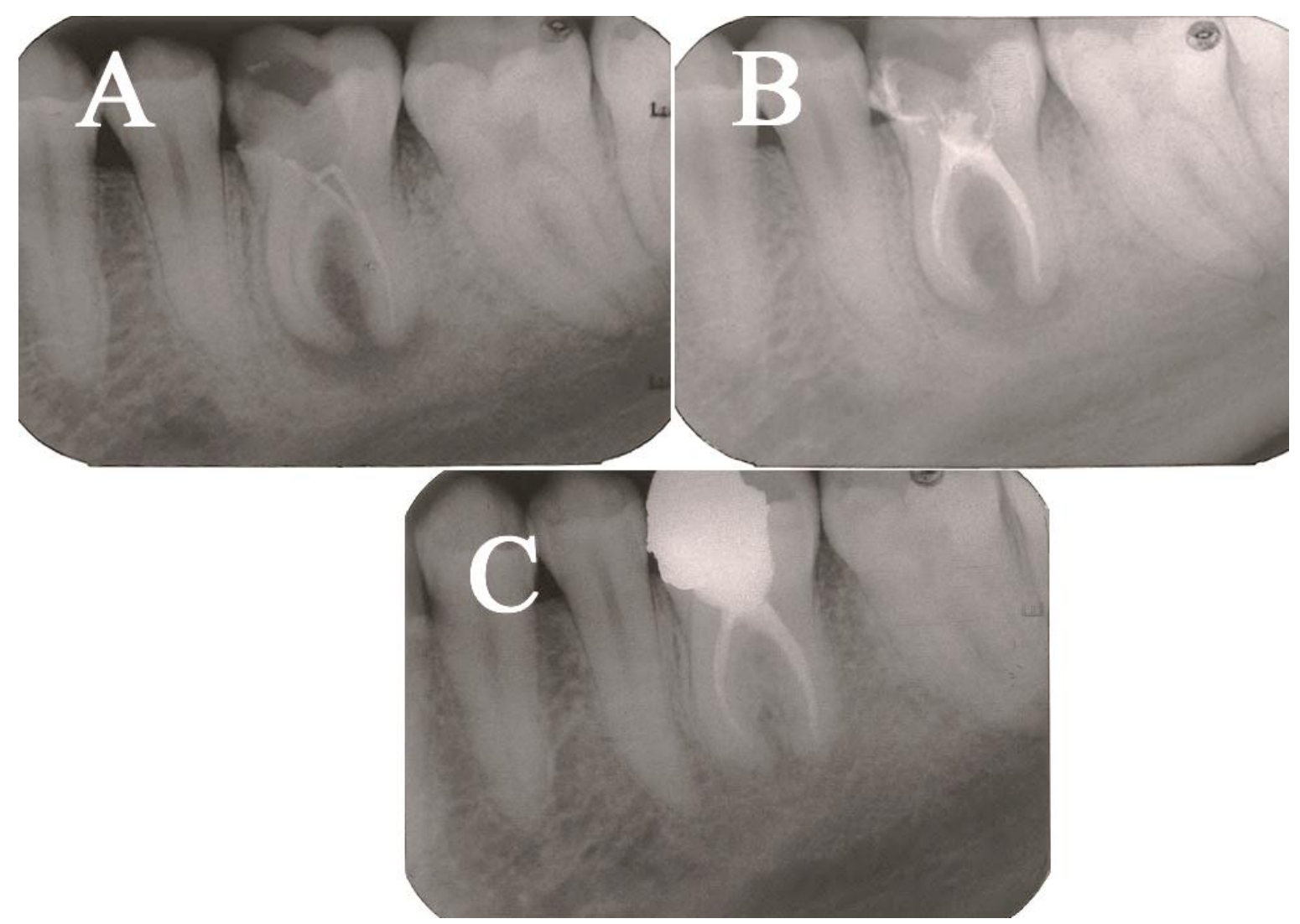

Figure 3. (A) Initial radiograph revealed the mandibular first molar with a large periapical lesion; (B) radiograph at the final endodontic treatment; $\mathbf{( C )}$ radiograph at one year, revealing complete repair. 


\section{Discussion}

Radiographic evaluation is the most widely used method for the detection of periapical lesions. Such lesions can be detected radiographically only when alveolar bone loss has been accompanied by cortical bone involvement during lesion development. For this reason, early-stage periapical lesions may not be visible radiographically (7).

Radiographic signs that indicate healing include a density change within the lesion, trabecular reformation, and lamina dura formation, particularly when they are associated with the clinical findings of an asymptomatic tooth and healthy soft tissue (8). Caliskan (9) observed healing within 2 years of treatment in approximately $70 \%$ of patients with periapical lesions. Other authors $(10,11)$ have reported the complete disappearance of periapical lesions within 1 to 12 months after treatment. In the present paper, we observed the initiation of periapical healing at 3 months after treatment and complete healing after 12 months.

Some authors have recommended intracanal medication as a non-surgical treatment of teeth with periapical lesions. Sjögren et al. (12) found that the use of a calcium hydroxide dressing for 1 week efficiently removed bacteria from the root canals. Beyond the apex, calcium hydroxide exhibits antiinflammatory and antibacterial activity, neutralizes acid products, and activates alkaline phosphatase (13). Caliskan and Türkün (11) found that the use of calcium hydroxide resulted in periapical healing, especially in young patients. We used calcium hydroxide dressings in the cases reported here.

Drainage is an important factor in the conservative management of large periapical lesions. Fernandes and Ataide (14) used the aspiration technique to achieve healing in a large periapical lesion. Histological studies (15) have also confirmed the significant role of drainage in the healing of such lesions. Symptoms are reduced when proper drainage is achieved, and systemic antibiotics are not indicated (9). In the present cases, root-canal treatments were performed in two sessions without the use of antibiotics.

\section{Conclusion}

In the present cases, healing of periapical lesions by a non-surgical approach was obvious after a year. This confirms that large periapical lesions can respond positively to non-surgical treatment.

\section{Acknowledgments}

\author{
The authors deny any conflicts of interest \\ related to this study.
}

\section{References}

1. G. Taxonomy, ecology, and pathogenicity of the root canal flora. Oral Surg Oral Med Oral Pathol 1994; 78:522-30.

2. Barbakow FH, Cleaton-J ones PE, Friedman D. Endodontic treatment of teeth with periapical radiolucent areas in a general dental practice. Oral Surg Oral Med Oral Pathol 1981;51:552-9.

3. Hiatt WH. Pulpal periodontal disease. J Periodontol 1977;48:598-609.

4. Ramachandran Nair PN, Pajarola G, Schroeder HE. Types and incidence of human periapical lesions obtained with extracted teeth. Oral Surg Oral Med Oral Pathol Oral Radiol Endod 1996;81:93-102.

5. Eversole LR. Clinical outline of oral pathology: diagnosis and treatment. . 2nd ed. Philadelphia: Lea \& Febiger; 1984.

6. Hoen MM, LaBounty GL, Strittmatter EJ. Conservative treatment of persistent periradicular lesions using aspiration and irrigation. J Endod 1990; 16: 182-6.

7. Tanomaru-Filho $M$, Jorge EG, Duarte MA, Goncalves M, Guerreiro-Tanomaru JM. Comparative radiographic and histological analyses of periapical lesion development. Oral Surg Oral Med Oral Pathol Oral Radiol Endod 2009; 107:442-7.

8. Saatchi M. Healing of large periapical lesion: a non-surgical endodontic treatment approach. Aust Endod J 2007;33:136-40.

9. Caliskan MK. Prognosis of large cyst-like periapical lesions following nonsurgical root canal treatment: a clinical review. Int Endod J 2004; 37:408-16.

10. Oztan MD. Endodontic treatment of teeth associated with a large periapical lesion. Int Endod J 2002; 35:73-8.

11. Caliskan MK, Turkun M. Periapical repair and apical closure of a pulpless tooth using calcium hydroxide. Oral Surg Oral Med Oral Pathol Oral Radiol Endod 1997;84:683-7.

12. Sjogren U, Figdor D, Spangberg L, Sundqvist G. The antimicrobial effect of calcium hydroxide as a short-term intracanal dressing. Int Endod J 1991;24: 119-25.

13. Farhad A, Mohammadi Z. Calcium hydroxide: a review. Int Dent J 2005;55:293-301.

14. Fernandes $M$, De Ataide I. Non-surgical management of a large periapical lesion using a simple aspiration technique: a case report. Int Endod J ; 43:536-42. 
15. Fujii H, Machida Y. Histological study of therapy for infected nonvital permanent teeth with incompletely formed apices. Bull Tokyo Dent Coll 1991;32:35-45. 